\title{
Ectopia lentis et pupillae syndrome in three generations
}

\author{
J R M Cruysberg, A Pinckers
}

Institute of

Ophthalmology,

University Hospital

Nijmegen, Nijmegen,

the Netherlands

J R M Cruysberg

A Pinckers

Correspondence to:

J R M Cruysberg, $M D$

Institute of Ophthalmology,

University Hospital

Nijmegen, PO Box 910i,

$6500 \mathrm{HB}$ Nijmegen, the

Netherlands.

Accepted for publication

5 September 1994

\begin{abstract}
In nine members from three generations and in a distant relative, at least three significant characteristics of the ectopia lentis et pupillae syndrome were established including ectopia lentis, ectopia pupillae, persistent pupillary membrane, iris transillumination, and poor pupillary dilatation. All patients developed bilateral cataract before the age of $\mathbf{4 0}$ years, and two patients presented with intermittent acute intraocular hypertensive crises. Not only the high number of patients in one family, but also the occurrence in three generations is very exceptional for the ectopia lentis et pupillae syndrome. Although the syndrome is said to be inherited in an autosomal recessive mode, in this family, a mother to son and a mother to daughter transmission were present. Pedigree analysis yielded arguments in favour of an autosomal dominant inheritance with reduced penetrance. A biochemical correlation was not identified.

(Br F Ophthalmol 1995; 79: 135-138)
\end{abstract}

Ectopia lentis et pupillae (ELP) is a congenital hereditary disorder in which there is displacement of the lenses and the pupils, associated with other ocular anomalies, but without systemic manifestations. ${ }^{1-16}$ The condition is usually bilateral, with the lenses and pupils displaced in opposite directions. However, a marked variability in expression is observed between the two eyes of a patient and among affected members of a family. ${ }^{1316}$ The ELP syndrome must be differentiated from displacement of the pupillary position (corectopia) as a result of intraocular surgery, or other progressive ocular disorders - for example, essential iris atrophy, Chandler's syndrome, Rieger's syndrome, and intraocular inflammation. ${ }^{17}$

We examined a patient with classic ELP syndrome and studied the family because the mother of the proposita was also affected.

\section{Patients and methods}

The proposita (VII-24), a 36-year-old woman, presenting with congenital bilateral ectopia lentis et pupillae, asked for genetic counselling

\begin{tabular}{|cl|}
\hline$x$ & Proposita \\
+ & Examined \\
\hline & Coceased \\
& Affected male \\
Affected female & Number of children, both sexes \\
\hline
\end{tabular}

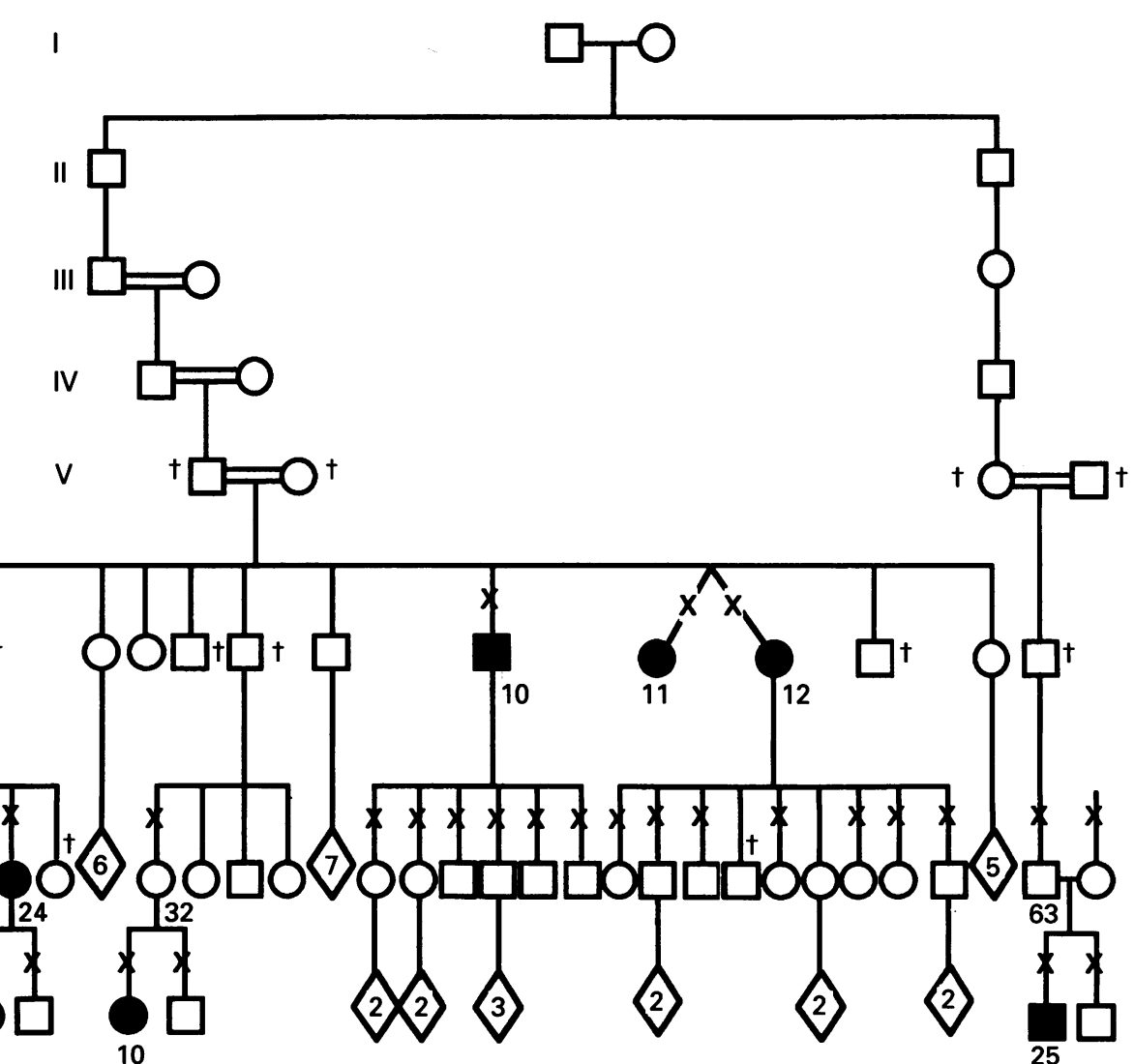

Figure 1 Pedigree of a family with ectopia lentis et pupillae syndrome in three generations, showing 10 affected patients. The spouses of unaffected family
members (VII-32 and VII-63) were examined and found to be normal. 
Table 1 Findings in patients with the ectopia lentis et pupillae syndrome

\begin{tabular}{|c|c|c|c|c|c|c|c|c|c|c|c|c|c|c|c|c|c|c|c|c|}
\hline \multirow{2}{*}{$\begin{array}{l}\text { Generation } \\
\text { Patient No } \\
\text { Sex }(M / F) \\
\text { Eye }(R / L)\end{array}$} & \multicolumn{2}{|c|}{$\begin{array}{l}V I \\
2 \\
F\end{array}$} & \multicolumn{2}{|l|}{$\begin{array}{l}V I \\
4 \\
F\end{array}$} & \multicolumn{2}{|l|}{$\begin{array}{l}V I \\
10 \\
M\end{array}$} & \multicolumn{2}{|l|}{$\begin{array}{l}V I \\
11 \\
F\end{array}$} & \multicolumn{2}{|l|}{$\begin{array}{l}V I \\
12 \\
F\end{array}$} & \multicolumn{2}{|c|}{$\begin{array}{l}V I I \\
10 \\
F\end{array}$} & \multicolumn{2}{|l|}{$\begin{array}{l}V I I \\
21 \\
M\end{array}$} & \multicolumn{2}{|l|}{$\begin{array}{l}V I I \\
24 \\
F\end{array}$} & \multicolumn{2}{|l|}{$\begin{array}{l}\text { VIII } \\
10 \\
F\end{array}$} & \multicolumn{2}{|l|}{$\begin{array}{l}\text { VIII } \\
25 \\
M\end{array}$} \\
\hline & $R$ & $L$ & $R$ & $L$ & $R$ & $L$ & $R$ & $L$ & $R$ & $L$ & $R$ & $L$ & $R$ & $L$ & $R$ & $L$ & $R$ & $L$ & $R$ & $L$ \\
\hline Ectopia lentis & + & + & + & + & + & + & + & + & + & + & + & + & + & + & + & + & + & + & + & + \\
\hline Ectopia pupillae & - & - & + & + & - & - & + & + & - & - & - & - & + & + & + & + & - & - & + & + \\
\hline Pupillary membrane & - & - & \# & \# & + & + & + & + & - & - & - & - & - & - & - & - & + & + & + & - \\
\hline Iris transillumination & \# & \# & \# & \# & + & + & + & + & - & - & + & + & + & + & + & + & - & - & + & + \\
\hline Poor pupillary dilatation & \# & \# & \# & \# & + & + & + & + & \# & \# & $\#$ & \# & + & + & + & + & \# & \# & + & + \\
\hline Axial length & $\#$ & \# & \# & \# & \# & 25 & 24 & 23 & 21 & 21 & 21 & 21 & 30 & 31 & 23 & 24 & 20 & 20 & 21 & 21 \\
\hline Corneal diameter (mm) & \# & \# & \# & \# & 11 & 12 & \# & \# & \# & 11 & 11 & 12 & 11 & 11 & 10 & 10 & 11 & 12 & 11 & 11 \\
\hline Corneal radius (mm) & \# & \# & \# & \# & $7 \cdot 7$ & $7 \cdot 7$ & \# & \# & $7 \cdot 4$ & $7 \cdot 4$ & \# & \# & $7 \cdot 9$ & $7 \cdot 9$ & $8 \cdot 0$ & 7.9 & $7 \cdot 3$ & $7 \cdot 2$ & $7 \cdot 6$ & $7 \cdot 7$ \\
\hline Cataract & \# & \# & \# & \# & + & + & + & + & + & + & + & + & + & + & + & + & + & + & + & + \\
\hline Glaucoma & + & + & + & + & + & + & + & + & + & + & - & - & + & + & - & + & - & - & - & - \\
\hline Retinal detachment & - & - & + & - & + & - & - & - & + & - & - & - & - & + & - & - & - & - & - & - \\
\hline Uveitis & - & - & - & - & + & + & - & - & + & + & - & - & - & - & - & - & - & - & - & - \\
\hline Poor vision $(<6 / 20)$ & + & + & + & + & + & - & + & - & + & + & - & + & + & + & + & - & + & + & + & + \\
\hline
\end{tabular}

-=Condition absent; $+=$ condition present; \#=condition not examined.

because several members of her family had poor vision. She was diagnosed elsewhere as having Rieger's syndrome. The patient and her relatives underwent complete ophthalmic examinations, including measurement of the refractive error by subjective techniques (in adults) or cycloplegic retinoscopy (in children), corrected visual acuity measurement, slit-lamp biomicroscopy of the anterior segment before and after pupillary dilatation, ophthalmoscopy, and applanation tonometry. If ectopia lentis was diagnosed, measurement of the corneal diameter (ruler), corneal curvature (Javal ophthalmometer), and axial length (A scan ultrasonography) were performed. Photographic documentation was performed as previously described. ${ }^{18}$ Several members of the family had already been examined in our department. At the time of this study, the two oldest aunts of the proposita were deceased. A genealogical study was performed in order to search for consanguinity between the parents and maternal grandparents of the proposita. Later on, a distant relative (VIII-25) also presented with congenital bilateral ELP, and the genealogical study was extended. A number of patients underwent elaborate general examinations in order to rule out systemic and metabolic disorders, such as Marfan's syndrome and homocystinuria.

\section{Results}

In one family, we observed 10 patients with a congenital syndrome characterised by bilateral

Table 2 Clinical findings in the ectopia lentis et pupillae syndrome in affected members of one family

\begin{tabular}{lcr}
\hline Condition & $\begin{array}{c}\text { No of abnormal patients } \\
\text { No of examined patients }\end{array}$ & $\%$ \\
\hline Ectopia lentis & $10 / 10$ & 100 \\
Ectopia pupillae & $5 / 10$ & 50 \\
Persistent pupillary membrane & $4 / 9$ & 44 \\
Iris transillumination & $6 / 8$ & 75 \\
Poor pupillary dilatation & $5 / 5$ & 100 \\
Cataract & $8 / 8$ & 100 \\
Before age 20 years & $3 / 8$ & 38 \\
At age 40 years & $8 / 8$ & 700 \\
Glaucoma & $7 / 10$ & 40 \\
Retinal detachment & $4 / 10$ & 20 \\
Uveitis & $2 / 10$ & 100 \\
Poor vision $(<6 / 20)$ & $10 / 10$ & \\
\hline
\end{tabular}

ectopia lentis, and associated abnormalities of the pupil (ectopia pupillae, persistent pupillary membrane, poor pupillary dilatation) and iris (iris transillumination, excentric circular folds). Other ocular complications (cataract, glaucoma, uveitis, retinal detachment), high myopia, and poor vision were also seen. Systemic abnormalities were not found. The family pedigree is shown in Figure 1 and the clinical features are summarised in Tables 1 and 2. The proposita (Figure 2; VII-24), her brother (VII-21), mother (VI-4), a maternal aunt (VI-11), and a distant relative (VIII-25) all had classic ELP syndrome, whereas other family members showed ectopia lentis associated with other major signs of the syndrome. In one case (VI-10), the persistent pupillary membrane was so dense that surgery was needed to open the pupil. All the patients diagnosed as ELP had a history of poor vision. There was no history of poor vision in the grandparents (V-1 and V-2) of the proposita. The syndrome was present in five patients of generation VI, in three patients of generation VII, and in two patients of generation VIII. One affected female (VI-2) had an affected daughter, whereas another affected female (VI-4) transmitted the trait to a son and a daughter. The spouses of the unaffected family members, VII-32 and VII-63, were examined and found to be normal.

The maternal grandparents of the proposita were consanguineous. In fact there was consanguinity in three successive generations, but consanguinity of the parents of the proposita could not be demonstrated (Fig 1). The great grandparents, but not the parents of the distant relative (VIII-25), were consanguineous.

None of the affected family members had any systemic abnormalities related to disorders associated with ectopia lentis. In three patients, homocystinuria was ruled out with certainty by serum evaluation in the fasting state and after methionine loading. One patient (VII-10) underwent extensive investigations for metabolic disease: there were no abnormal findings of the amino acids, organic acids, purines, pyrimidines, mucopolysaccharides, oligosaccharides, neuraminic acid, galactitol, and sorbitol in plasma and urine. 


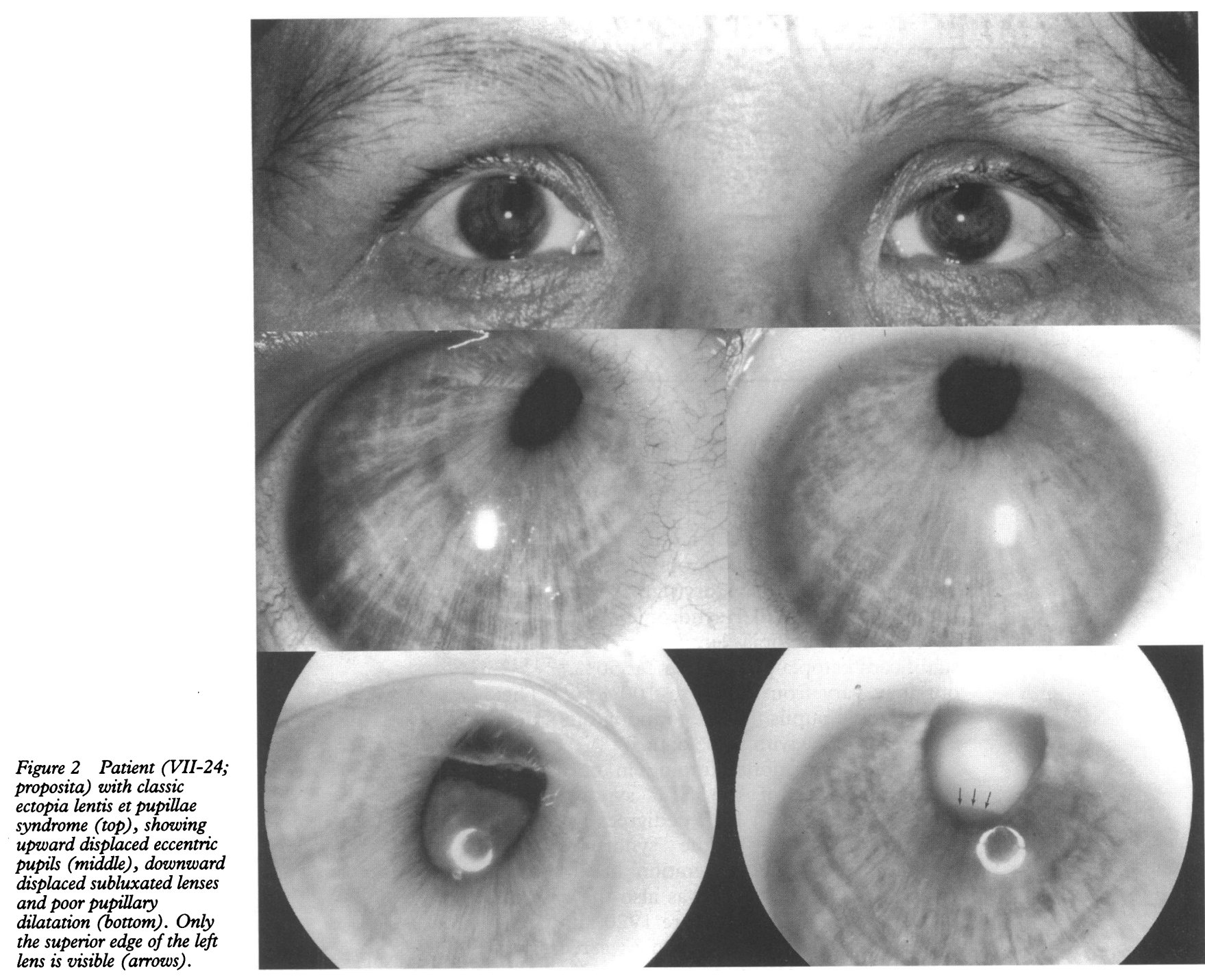

\section{Discussion}

The patients of this study fulfil the criteria for the diagnosis ELP syndrome: in five patients, the characteristic picture of bilateral ectopia lentis with congenital ectopia of oval or slitshaped pupils was present. In the remaining five patients there were, in addition to bilateral ectopia lentis, a number of symptoms which are described in the studies of the ELP syndrome as significant, such as transillumination of the iris periphery, ${ }^{1316}$ a dense pupillary membrane, ${ }^{61316}$ poor pupillary dilatation despite repeated phamacological attempts, ${ }^{13-16}$ high axial myopia, ${ }^{416}$ poor vision, ${ }^{14} 16$ a high prevalence of ocular complications at young age - for example, cataract, ${ }^{313}$ glaucoma, ${ }^{4}$ uveitis, retinal detachment, ${ }^{4}$ and lack of systemic disorders known to be associated with ectopia lentis. ${ }^{19}$

Other causes of ectopia pupillae were ruled out. Ectopia pupillae simplex (EPS) usually is inherited as an autosomal dominant trait without ectopia lentis. Rieger's syndrome is characterised by a prominent Schwalbe's line all around the corneal periphery. There is often hypoplasia of the iris stroma with through and through holes in the iris, causing polycoria and corectopia (ectopia pupillae). Marked corectopia is almost always unilateral in progressive essential iris atrophy, a subtype of the iridocorneal endothelial (ICE) syndrome, which includes disorders of the corneal endothelium with varying degree of endothelialisation of the anterior chamber angle and iris surface.

Ectopia lentis simplex (ELS) is inherited as an autosomal dominant trait, but the existence of an autosomal recessive form also has been reported..$^{20-22}$ Dominantly inherited ectopia lentis simplex is usually bilateral and symmetrical, with the lenses dislocated upward and laterally, but without ectopic pupils. ${ }^{23}$

None of our patients showed clinical signs of Marfan's syndrome, in which ectopia lentis is commonly present and iris transillumination has been documented clinically. ${ }^{24}$ As with ectopia lentis simplex, our patients showed lenticular myopia, amblyopia, cataract, glaucoma, retinal detachment, and poor vision. Compared with other authors ${ }^{16}$ our patients show a remarkably high prevalence of cataract before the age of 40 years. Intermittent acute intraocular hypertensive crises occurred in two affected members of generation VI. Enlarged corneal diameters ${ }^{13} 16$ were not found. Microspherophakia, another symptom sometimes described in the ELP syndrome, ${ }^{13}$ was not found.

In some respects the presented family is unique. Ten patients with the ELP syndrome in one pedigree is exceptional. Most pedigrees contain three, ${ }^{5} 6812-1416$ sometimes four, ${ }^{4}$ and rarely five patients. ${ }^{1}$ Because the presence of 
Table 3 Ectopia lentis et pupillae syndrome in the literature

\begin{tabular}{|c|c|c|c|c|c|c|c|}
\hline Reference & $\begin{array}{l}\text { Number } \\
\text { of } \\
\text { pedigrees }\end{array}$ & $\begin{array}{l}\text { Number } \\
\text { of } \\
\text { generations }\end{array}$ & $\begin{array}{l}\text { Number } \\
\text { of } \\
\text { patients }\end{array}$ & $\begin{array}{l}\text { Male/ } \\
\text { female } \\
\text { ratio }\end{array}$ & $\begin{array}{l}\text { Patients/ } \\
\text { pedigree }\end{array}$ & $\begin{array}{l}\text { Ectopia } \\
\text { lentis } \\
\text { (eyes) }\end{array}$ & $\begin{array}{l}\text { Ectopia } \\
\text { pupillae } \\
\text { (eyes) }\end{array}$ \\
\hline 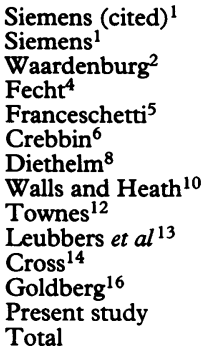 & $\begin{array}{l}1 \\
1 \\
1 \\
2 \\
1 \\
1 \\
1 \\
1 \\
3 \\
1 \\
8 \\
1\end{array}$ & $\begin{array}{l}1 \\
1 \\
1 \\
1 \\
1 \\
1 \\
2 \\
1 \\
1 \\
1 \\
1 \\
3\end{array}$ & $\begin{array}{r}5 \\
1 \\
4 \\
5 \\
1 \\
2 \\
3 \\
2 \\
6 \\
2 \\
16 \\
10\end{array}$ & $\begin{array}{c}13 / 13 \\
1 / 4 \\
0 / 1 \\
3 / 1 \\
4 / 1 \\
1 / 0 \\
1 / 1 \\
0 / 3 \\
2 / 0 \\
3 / 3 \\
2 / 0 \\
11 / 5 \\
3 / 7 \\
44 / 39\end{array}$ & $\begin{array}{l}5 \\
1 \\
4 \\
2,3 \\
1 \\
2 \\
3 \\
2 \\
1,2,3 \\
2 \\
1,2,3 \\
10\end{array}$ & $\begin{array}{r}10 \\
2 \\
6 \\
9 \\
2 \\
4 \\
5 \\
4 \\
12 \\
4 \\
30 \\
20 \\
108\end{array}$ & $\begin{array}{r}10 \\
2 \\
2 \\
7 \\
2 \\
2 \\
2 \\
4 \\
8 \\
4 \\
19 \\
10 \\
72\end{array}$ \\
\hline
\end{tabular}

ectopic pupils is a selection criterion for the diagnosis of ELP syndrome, the pedigrees with only one affected patient for obvious reasons will show a $100 \%$ prevalence of ectopia pupillae. However, many studies show that if there are more patients in one family, ectopia pupillae is not an obligatory sign. ${ }^{45101316} \mathrm{In}$ pedigrees with the ELP syndrome, the number of eyes with ectopia lentis presenting with significant ectopia pupillae is near $50 \%, 451316$ but may vary from $33 \%{ }^{4}$ to $100 \% .^{12}{ }^{14}$ The $50 \%$ ectopic pupils that we found in our study is in accordance with these data.

Another exceptional finding in our study is the presence of the ELP syndrome in three generations. In ELP pedigrees from the literature (Table 3), the syndrome was present in only one generation in 20 pedigrees. ${ }^{1}$ 4-68 12-14 16 This was also the case in 11 pedigrees published before 1920 and cited by Siemens. ${ }^{1}$ ELP is inherited as a recessive trait. ${ }^{511}$ François ${ }^{11}$ summarised publications from 1885 to 1947 and noted that consanguinity has been reported in many studies. $\mathrm{He}$ noted further that there were no exceptions to the concept of an autosomal recessive inheritance. An autosomal recessive inheritance of the ELP syndrome is suggested by the occurrence in several siblings of one generation, consanguinity, 2451415 and an equal distribution between males and females. Extensive search of the literature resulted in only two pedigrees with more than one affected generation. In the report of Walls and Heath, ${ }^{10}$ two generations were affected, suggesting a dominant inheritance: a female with ELP had a son with normal pupils but with ectopia lentis in one eye; her twin sister had ectopia lentis in both eyes. Strebel and Steiger in 1915 reported the occurrence of ELP in four generations, in combination with myopia and cardiac disease. ${ }^{12}$

In our pedigree, the inheritance of the ELP syndrome is not unequivocal. There are arguments in favour of an autosomal recessive inheritance, because the parents of the proposita are consanguineous and, by history, not affected. In addition the parents of the patients VIII-10 and VIII-25 were not affected. Furthermore five affected individuals (VI-10, VI-12, VII-10, VII-21, VII-24) had 24 normal children. However, arguments for a dominant inheritance are found in the fact that two affected persons had three affected children, and that the ELP syndrome occurred in three generations. Pseudodominance could not be proved despite extensive genealogical investigations. A possible explanation is that in our pedigree the ELP syndrome is transmitted as an autosomal dominant trait with reduced penetrance and variable expression.

A strict distinction into an autosomal recessive inherited ELP syndrome, an autosomal dominant inherited ectopia pupillae syndrome or an autosomal dominant inherited ectopia lentis syndrome, is in our opinion too artificial and probably no longer justified. In order to solve the many questions, we must go back to the genetic mechanisms involved in the development of both lens and iris. Waardenburg $^{25}$ wrote in 1932: 'it is very likely that the recessive ectopia lentis syndrome and the ectopia pupillae et lentis syndrome, at least in a number of cases, have a common genetic origin.' Whatever the transmission, the affected members of the pedigree we present here are suffering from a common genetic defect.

Supported by a grant from the Stichting Researchfonds Oogheelkunde.

1 Siemens HW, Ueber die Aetiologie der Ectopia lentis et pupillae nebst einigen allgemeinen Bemerkungen übe Vererbung bei Augenleiden. Graefes Arch Klin Exp Ophthalmol 1920; 109: 359-83.

2 Waardenburg PJ. Over het erfelijkheidsmoment bij de aangeboren verplaatsing van de pupil en lens. Genetica 1924; 6: 337-82.

3 Zeeman WPC. Ueber ectopia pupillae et lentis congenita. Klin Monatsbl Augenheilkd 1925; 74: 325-38.

Fecht W. Ueber familiäre Linsenluxation. $Z$ Augenheilkd $1927 ; 62: 162-8$

5 Franceschetti A. Ectopia lentis et pupillae congenita als rezessives Erbleiden und ihre Manifestierung durch Konsanguinität. Klin Monastbl Augenheilkd 1927; 78: 351-62.

6 Crebbin AR. Persistent pupillary membrane and congenita ectopia lentis. Am f Ophthalmol 1929; 12: 87-90.

7 Clarke CC. Ectopia lentis. A pathologic and clinical study. Arch Ophthalmol 1939; 21: 124-53.

8 Diethelm W. Ueber Ectopia lentis ohne Arachnodaktylie und ihre Beziehungen zur Ectopia lentis et pupillae. Ophthalmologica 1947; 114: 16-32.

9 Lund A, Sjontoft F. Congenital ectopia lentis. Acta Ophthalmol 1950; 29: 33-48.

10 Walls GL, Heath GG. Dominant ectopia lentis et pupillae. Am f Hum Genet 1959; 11: 166-8.

11 François J. Hereditary in ophthalmology. St Louis: Mosby, 1961: 161-4.

12 Townes PL. Ectopia lentis et pupillae. Arch Ophthalmo 1976; 94: 1126-8.

13 Luebbers JA, Goldberg MF, Herbst R, Hattenhauer J, Maumenee AE. Iris transillumination and variable expression in ectopia lentis et pupillae. Am $\mathcal{f}$ Ophthalmol 1977; 83: 647-56.

14 Cross HE. Ectopia lentis et pupillae. Am $\mathcal{f}$ Ophthalmol 1979; 88: $381-4$

15 L'Abbate A, Santorelli P, Pesando P. Ectopia della lenta della pupilla. Valutazione clinica in 4 casi con follow up di 26 anni. Boll Ocul 1984; 63: 3-4, 157-66.

16 Goldberg MF. Clinical manifestations of ectopia lentis et pupillae in 16 patients. Ophthalmology 1988; 95: 1080-7.

17 Cross HE, Maumenee AE. Progressive, spontaneous dissolution of the iris. Surv Ophthalmol 1973; 18: 186-99.

18 Aandekerk AL, Cruysberg, JRM. Photography of ectopia lentis. F Audiovis Media Med 1987; 10: 87-9.

19 Nelson LB, Maumenee IH. Ectopia lentis. Surv Ophthalmol 1982; 27: $143-60$

20 McKusick VA. Primordial dwarfism and ectopia lentis. Am F Hum Genet 1955; 7: 189-98.

21 Ruiz C, Rivas F, Villar-Calvo VM, Serrano-Lucas JI, Cantú JM. Familial simple ectopia lentis; a probable autosomal recessive form. Ophthalmic Paediatr Genet 1986; 7: 81-4.

$22 \mathrm{Al}-S a l e m \mathrm{M}$. Autosomal recessive ectopia lentis in two Arab family pedigrees. Ophthalmic Paediat Genet 1990; 11 123-7.

23 Falls HF, Cotterman CW. Genetic studies on ectopia lentis A pedigree of simple ectopia of the lens. Arch Ophthalmo 1943; 30: 610-20.

24 Maumenee IH. The eye in the Marfan syndrome. Trans Am Ophthalmol Soc 1981; 79: 684-733.

25 Waardenburg PJ. Das menschliche Auge und seine Erbanlage. The Hague: Martinus Nijhof, 1932: 315. 